\title{
O SUS e as políticas sociais: Desafios contemporâneos para a atenção primária à saúde
}

\author{
SUS and social policies: Contemporary challenges for primary health care \\ SUS y las políticas sociales: Desafíos contemporáneos para la atención primaria de salud
}

\author{
Welington Serra Lazarini ${ }^{1} \mathbb{C}$, Francis Sodré $^{1} \mathbb{D}$ \\ ${ }^{1}$ Universidade Federal do Espírito Santo (UFES). Vitória, ES, Brasil.
}

\section{Resumo}

Este artigo constitui-se em um estudo teórico, cuja premissa é a imposição feita pelo atual estágio do capitalismo aos países pobres, entre eles o Brasil, que visa flexibilizar a estruturação de suas políticas sociais, ameaçando conquistas importantes, como é o caso do Sistema Único de Saúde (SUS). Como objetivo, importou analisar as políticas sociais no Brasil no contexto do capitalismo contemporâneo, em que predomina a mais fetichizada forma do capital, qual seja, o capital portador de juros, e seus desdobramentos para o SUS. Além disso, buscou-se compreender o papel dos organismos internacionais, especialmente o Banco Mundial, neste contexto. A primeira parte apresenta uma discussão acerca da crise do Estado de Bem-Estar e da reconfiguração das políticas sociais, segundo a lógica da fase atual do capitalismo. Além disso, discute a disputa pelo fundo público e sua relevância para o processo de acumulação e expansão do capital portador de juros. A segunda parte expõe o papel estratégico dos organismos internacionais, sobretudo o Banco Mundial, como porta-voz da agenda neoliberal. Trata da influência do Banco Mundial sobre a política interna dos Estados, de modo a articular a geopolítica internacional, segundo os "interesses dos mercados". Por fim, fazem-se alguns apontamentos para o futuro do sistema de saúde brasileiro, principalmente para a Atenção Primária à Saúde.

Palavras-chave: Política Social; Banco Interamericano de Reconstrução e Desenvolvimento; Sistema Único de Saúde; Atenção Primária à Saúde
Como citar: Lazarini WS, Sodré F. O SUS e as políticas sociais: Desafios contemporâneos para a atenção primária à saúde. Rev Bras Med Fam Comunidade. 2019;14(41):1904. http://dx.doi.org/10.5712/rbmfc14(41)1904
Autor correspondente: Welington Serra Lazarini. E-mail: welingtonsı@ hotmail.com Fonte de financiamento: declaram não haver.

\section{Parecer CEP:}

\section{não se aplica.}

Procedência e revisão por pares: revisado por pares. Recebido em: 29/10/2018. Aprovado em: 29/11/2018. 


\begin{abstract}
This paper is a theoretical study whose premise is the imposition made by the current stage of capitalism on poor countries, among them Brazil, which aims to make the structuring of its social policies more flexible, threatening important achievements, such as the Unified Health System. It was important, as a goal, to analyze the Brazilian social policies in the context of contemporary capitalism, in which the most fetishized form of capital, namely, the interest-bearing capital, and its unfolding for the SUS, predominates. We also sought to understand the role of international organizations, especially the World Bank, in this context. The first part shows a discussion about the crisis of the Welfare State and the reconfiguration of social policies according to the rationale of the current stage of capitalism. Furthermore, it discusses the dispute over public funds and its relevance to the process of accumulated and expanded interest-bearing capital. The second part shows the strategic role of international organizations, especially the World Bank, as the spokesperson for the neoliberal agenda. It addresses the influence of the World Bank on the domestic policy of the states so as to articulate international geopolitics according to "market interests". Finally, some remarks are made regarding the future of the Brazilian health system, particularly for Primary Health Care.
\end{abstract}

Keywords: Social Policy; International Bank for Reconstruction and Development; Unified Health System; Primary Health Care

\title{
Resumen
}

Este artículo se constituye en un estudio teórico, cuya premisa es la imposición hecha por la actual fase del capitalismo a los países pobres, entre ellos Brasil, y que pretende flexibilizar la estructuración de sus políticas sociales, amenazando logros importantes, como es el caso del Sistema Único de Salud. Como objetivo, importó analizar las políticas sociales en Brasil en el contexto del capitalismo contemporáneo, en el que predomina la más fetichizada forma del capital, cuál es, el capital portador de interés, y sus desdoblamientos para SUS. Además, se buscó comprender el papel de los organismos internacionales, especialmente el Banco Mundial, en este contexto. La primera parte presenta una discusión acerca de la crisis del Estado de Bienestar y de la reconfiguración de las políticas sociales, según la lógica de la fase actual del capitalismo. También se discute la disputa por los fondos públicos y su relevancia para el proceso de acumulación y expansión del capital portador de interés. La segunda parte expone el papel estratégico de los organismos internacionales, sobre todo el Banco Mundial, como portavoz de la agenda neoliberal. Trata de la influencia del Banco Mundial sobre la política interna de los Estados, para articular la geopolítica internacional según los "intereses de los mercados". Por último, se hacen algunos apuntes para el futuro del sistema de salud brasileño, en particular para la Atención Primaria de Salud.

Palabras clave: Política Social; Banco Internacional de Reconstrucción y Fomento; Sistema Único de Salud; Atención Primaria de Salud

\section{Introdução}

Após quase três décadas desde a sua criação, o Sistema Único de Saúde (SUS) atravessa um dos períodos mais desafiadores da sua história. Imerso em tensões que acirram o cenário político e econômico, o sistema tem sofrido com os sucessivos cortes no orçamento e com as mudanças substantivas na conformação das políticas de saúde no Brasil.

A fim de entender os rumos da implementação das políticas de saúde no país, faz-se necessário compreendê-la enquanto política social e situá-la dentro do jogo de interesses e contradições no qual está inserida. Fleury e Ouverney ${ }^{1}$ consideram a política de saúde como uma política social, uma vez que a mesma assegura o acesso daqueles que são considerados usuários dos sistemas de proteção social a um conjunto de benefícios. Pensar a saúde como direito é, antes de tudo, respeitar a condição de cidadania em sua plenitude, uma vez que a plena participação dos indivíduos na sociedade política se realiza a partir de sua inserção como cidadãos. ${ }^{1}$

Historicamente, o SUS é reconhecido como a maior reforma da área social brasileira. Embora seu arcabouço conceitual tenha sido ancorado nos pilares democráticos da universalidade, equidade e integralidade, ele sofre, desde a sua criação, com as tensões advindas do paradigma neoliberal. ${ }^{2} \mathrm{~A}$ agenda de reformas do Estado ganhou força no Brasil no início da década de 1990, em uma clara tentativa de responder às demandas da globalização da economia e de enfrentar a crise que se instalara. Assim, 
contraditoriamente, ao passo que a conquista do direito à saúde orientou o acesso irrestrito aos serviços de saúde no país, sua materialização ocorreu em meio a um expressivo mercado de serviços e empresas de planos de saúde privados. ${ }^{3}$

Muito apropriadamente, Behring e Boschetti ${ }^{4}$ chamam esse processo de "contrarreforma", pois suas diretrizes foram na contramão dos avanços e direitos conquistados pela classe trabalhadora. Os pressupostos da contrarreforma eram a redefinição das funções do Estado, objetivando a redução do seu tamanho, mediante a proposição de plataformas de privatização e terceirização; a redução do grau de interferência do Estado na economia, por meio da reforma econômica orientada para o mercado e da adoção de programas de desregulação; e o aumento da governabilidade do Estado. ${ }^{5-7}$ Essa proposição de reconfiguração das políticas sociais no Brasil, de caráter neoliberal, contou com a influência direta de organismos internacionais como o Banco Mundial, ${ }^{8}$ que passou a formular diversas diretrizes para o setor saúde no início na década de 1980, endereçadas, principalmente, aos países pobres.

Diante do exposto, este artigo constitui-se em um estudo teórico, cuja premissa é a imposição feita pelo atual estágio do capitalismo aos países em desenvolvimento, entre eles o Brasil, que visa flexibilizar a estruturação de suas políticas sociais, ameaçando conquistas importantes, como é o caso do SUS. Logo, importa analisar as políticas sociais no Brasil no atual contexto do capitalismo contemporâneo e seus desdobramentos para o SUS, sobretudo no que tange à Atenção Primária a Saúde (APS). Além disso, busca-se compreender o papel dos organismos internacionais, especialmente o Banco Mundial, neste cenário.

A primeira parte do texto apresenta uma discussão acerca da crise do Estado de Bem-Estar e da reconfiguração das políticas sociais, segundo a lógica da fase atual do capitalismo. Além disso, discute a disputa pelo fundo público e sua relevância no cumprimento dos interesses do capital portador de juros.

A segunda parte expõe o papel estratégico dos organismos internacionais, sobretudo o Banco Mundial, como porta-voz da agenda neoliberal. Trata da influência daquele banco sobre a política interna dos Estados, de modo a articular a geopolítica internacional, segundo os interesses dos "mercados".

Por fim, apresentam-se alguns apontamentos para o futuro do sistema de saúde brasileiro e para a APS.

\section{A politica social em tempos de capitalismo financeiro: desafios contemporâneos}

Conforme os interesses envolvidos, o entendimento acerca das políticas sociais adquire contornos diferenciados. Neste texto, ela é compreendida como conjunto das ações relacionadas à ampliação, à reprodução e à modificação dos sistemas de proteção social, sejam elas transitórias ou permanentes. ${ }^{1}$

As políticas de proteção social emanam em meio às tensões vivenciadas a partir do processo de desenvolvimento das sociedades capitalistas industrializadas e suas consequências, como o aumento da divisão do trabalho, a expansão dos mercados e a perda das funções da seguridade das organizações tradicionais como a família. Desse modo, a busca por um novo pacto de solidariedade social foi necessária, dentro de um cenário marcado por uma ampla organização de vários seguimentos da sociedade. ${ }^{1}$ 
A materialização de tais políticas nos países centrais do capitalismo, a partir do fim da Segunda Guerra Mundial, ocorre por intermédio de uma concepção e uma prática inerentes ao capitalismo monopolista de Estado. Esta fase corresponde ao desenvolvimento do modo de produção na qual se evidenciou um aumento notável da concentração e centralização do capital. Esse fato se mostrou determinante para que a concorrência dos preços na indústria fosse aniquilada, possibilitando que uma empresa fosse dominando a outra. A aliança formada entre o capital bancário e o capital industrial nesse processo deu origem ao grande capital financeiro que, na prática, é quem controla a economia nos países capitalistas. ${ }^{9} \mathrm{~A}$ viabilidade das políticas sociais nesse processo se deu por intermédio do intervencionismo do Estado diante da produção e reprodução das relações na sociedade capitalista, com vistas à promoção da cidadania, o que caracterizou as chamadas políticas keynesianas. ${ }^{10}$

Assim, esse processo contribuiu para a formatação do Welfare State (Estado de Bem-Estar Social), nome pelo qual foram denominados os amplos sistemas de proteção social. É o resultado de um conjunto de fatores vivenciados na Europa em um momento histórico específico, cujo contexto deu origem a formação dos Estados Nacionais, a democracia de massas e o capitalismo industrial. ${ }^{1}$ Segundo Arretche, ${ }^{11}$ em extenso trabalho de revisão da produção acerca da emergência e desenvolvimento do Welfare State, várias são as teorias que se propõem explicar tal fenômeno. Algumas correntes atribuem maior importância a fatores de natureza econômica. Outras, por sua vez, consideram as questões políticas como prioritárias para o surgimento desses sistemas de proteção.

No período compreendido entre 1945 a meados dos anos 1970, o sistema capitalista experimentou um robusto crescimento econômico, que ficou conhecido como os "30 anos gloriosos". ${ }^{12}$ Neste período, de quase 30 anos, o sistema econômico apresentou resultados nunca vistos antes e que não viriam a se repetir depois de então. ${ }^{12}$ Ainda que as crises cíclicas tenham se feito presentes, a regulação posta pela intervenção do Estado nesse período foi determinante para atenuar os seus efeitos. ${ }^{12}$

Com o passar desse momento, entretanto, uma grave e profunda crise no capitalismo se iniciou, provocando desdobramentos que perduram até o presente momento. Em meados da década de 1960, iniciou-se um processo de esgotamento da fase expansiva da economia capitalista. Começava-se, então, a experimentar uma queda nas taxas de lucros. Assistia-se, nesse contexto, à insatisfação e ao fortalecimento do movimento sindical em diversos países. E assim, as políticas keynesianas já não conseguiam mais manter a sustentação. ${ }^{13}$

No intuito de superar a crise do Welfare State e promover o retorno à manutenção das taxas de lucro, o capital portador de juros ocupou o lugar de dominância no sistema econômico, sobretudo na forma de capital fictício. Embora não haja uma definição clara sobre capital fictício na obra de Marx, trata-se de uma das possibilidades do capital portador de juros, ou seja, é o capital investido em títulos de crédito, que confere aos investidores o direito de obterem parte dos lucros, por intermédio dos juros. Uma característica importante do capital fictício é sua autonomia em relação ao capital real. Marx aponta três formas principais de capital fictício: o capital bancário, a dívida pública e o capital acionário. ${ }^{14}$

Com a queda da taxa de juros e a diminuição da produtividade, a partir do final da década de 1960, sobretudo nos Estados Unidos e na Europa, a taxa de desemprego assumiu dimensões exorbitantes, em virtude da queda do nível de atividade nos diversos setores da economia. A fim de estabelecer as condições necessárias para a manutenção das elevadas taxas de lucro, novas tecnologias foram inseridas na dinâmica 
econômica. No que tange à esfera financeira, a não intervenção do Estado nas transações comerciais criou um ambiente favorável à liberalização monetária, a descompartimentalização dos mercados financeiros e a desintermediação, conferindo ao capital fictício possibilidade de crescimento nunca antes experimentado. ${ }^{15}$

Face ao exposto, a atual fase do capitalismo tem recebido a denominação de avançado, financeiro ou tardio. ${ }^{16,17}$ Desse modo, para compreender os motivos que levaram à crise do Estado de Bem-Estar Social, faz-se necessário entender quais interesses estão postos e orientam a estruturação das políticas sociais no Estado capitalista, lugar onde os conflitos entre o mercado e os interesses de parte da população - com vistas à manutenção dos direitos de cidadania - estão postos.

Inicialmente, o primeiro aspecto a ser considerado é o da mundialização financeira. ${ }^{18}$ Embora já estivesse em curso, tal processo de acumulação do capital adquire grande destaque, em termos de ampliação, a partir de 1990. A extinção da União Soviética, a mudança no regime dos países do Leste Europeu e a entrada da China na Organização Mundial do Comércio foram fatores importantes para a configuração da nova ordem geopolítica, segundo os interesses da atual fase do capitalismo. Outra questão importante refere-se à diminuição do papel do Estado na regulação dos fluxos dos mercados. Ou seja, há uma crescente ampliação da privatização de diversas funções anteriormente geridas pelo setor público, e que se tornaram alvo da ação do capital. ${ }^{15}$

O segundo ponto a ser destacado diz respeito justamente à centralidade que fora conferida ao capital financeiro. ${ }^{19}$ Ao contrário do período anterior, caracterizado pela produção dos bens e serviços como prioridade das empresas, no qual a principal fonte de lucro dos bancos decorria de empréstimos (sobretudo ao setor produtivo), as atividades financeiras ganharam outra perspectiva. Mantendo uma relação distanciada da produção, passaram a ser praticadas por diferentes atores, tais como instituições de variadas matizes, empresas, bancos e fundos de pensão. Nesse sentido, pode-se dizer que o capital portador de juros atinge sua forma mais fetichizada, uma vez que é capaz de realizar a reprodução do capital, sem que haja a necessidade de que ele passe, em seu ciclo, pela produção. ${ }^{15}$

Portanto, a forma atualmente predominante do capital manifesta-se de diferentes modos, seja por intermédio dos empréstimos subsidiados, na criação de empresas e de novos "entes públicos", ou nas parcerias público-privadas e nos contratos de gestão. ${ }^{20}$ Dessa forma, uma gama de possibilidades se abre, permitindo a diversificação das mercadorias e das atividades econômicas, e a ampliação dos mercados. ${ }^{20}$

Diante desse atual contexto, sob a égide do pensamento neoliberal, as políticas sociais adquirem novos contornos. Com a prerrogativa de se orientarem pela eficiência em detrimento das falhas apontadas durante o período do Estado Social no pós-Segunda Guerra, passam a ser configuradas como pluralismo de bem-estar, ou seja, provêm da articulação entre Estado, mercado e a sociedade, cujo objetivo é atender às necessidades básicas dos indivíduos, por meio do provimento de bens e serviços. ${ }^{21}$

Tais características revelam uma concepção de bem-estar bastante diferente da anterior. Para os neoliberais, ela está intrinsecamente ligada ao mérito individual, ou seja, distancia-se da ideia calcada na provisão de direitos sociais. Além disso, assumem um posicionamento de privilegiar a produção capitalista sem a intervenção do Estado, deixando o mercado e seus fluxos livres. ${ }^{21}$ Por fim, seguindo a lógica das "liberdades individuais" proposta por Sen, ${ }^{22}$ conecta o bem-estar à igualdade de oportunidades, sem se importar com a partilha dos resultados. 
Desse modo, um dos desdobramentos mais contundentes das políticas neoliberais refere-se à acentuada perda de importância das medidas de emprego adotadas, o que, consequentemente, promoveu a elevação das taxas de desemprego em vários pontos do globo. Além disso, outras medidas importantes foram tomadas, a saber: cortes em programas públicos, focalização das políticas sociais na pobreza extrema, achatamento dos salários e perda de inúmeros direitos sociais. ${ }^{23}$

A noção de "Estado mínimo" advogada pelos neoliberais adquire contorno estratégico para o alcance dos interesses hegemônicos na atual fase do capitalismo. ${ }^{24}$ Com isso, abriu-se uma janela de oportunidades no sentido de generalizar a privatização dos serviços públicos. Entretanto, tal estratégia não é assumida pelos seus idealizadores, que passam a associar a provisão de direitos à iniciativa privada, arquitetado sob a prerrogativa da eficiência dos serviços e do pluralismo de bem-estar. ${ }^{21}$ Logo, a questão central nesse debate não gira em torno da diminuição da presença do Estado na construção das políticas sociais, mas, sim, de sua função privativa de ordenador da manutenção dos direitos sociais conquistados. ${ }^{21}$

Se não bastasse destituir o Estado de grande parte de suas funções centrais, a lógica neoliberal impõe uma série de constrangimentos aos países, sobretudo àqueles mais pobres. No que se refere aos países da América Latina, a agenda neoliberal apontou para uma série de medidas que compunham, em última análise, a reforma dos sistemas de proteção social, cuja perspectiva apontava para a privatização, a descentralização e programas (fundos) sociais de emergências. ${ }^{25}$

Face ao exposto, há que se considerar a centralidade que o fundo público assume aos interesses do capital, sobretudo no que tange a exploração dos países periféricos. Conforme descreve Salvador, ${ }^{26}$ o fundo público se refere à mobilização dos recursos operados pelo Estado, com o objetivo de intervir na economia. Essa movimentação dos capitais pode ocorrer por intermédio das empresas públicas, pela via da política monetária e fiscal e, em grande parte, pelo orçamento público.

Grande parte dos recursos que compõem o fundo público é proveniente dos mais diversos impostos e taxas que são pagos diariamente pela população. É justamente o aumento da transferência de recursos do orçamento público para o pagamento de juros da dívida pública, o grande combustível alimentador dos ganhos dos rentistas, ou seja, com a financeirização da riqueza os recursos do fundo público são cada vez mais disputados pelos mercados. ${ }^{26}$ Esse movimento pressiona para um aumento das despesas do orçamento estatal, passando pela remuneração dos títulos públicos - importante fonte de rendimentos para os investidores institucionais - que são emitidos pelas autoridades monetárias e negociados no mercado financeiro. Nesse processo, encontram-se incentivos fiscais e isenção de tributos à custa do fundo público. ${ }^{26}$

O fundo público foi o alicerce das políticas macroeconômicas nos países centrais do capitalismo no pós-Segunda Guerra Mundial, que adotaram o Estado de Bem-Estar Social. Tal estratégia se tornou fundamental para o processo de acumulação capitalista, além de viabilizar o financiamento das políticas sociais. Cabe destacar que até hoje o fundo público configura-se em importante mecanismo para a expansão do capitalismo; ${ }^{27}$ logo, apresenta-se na sociedade uma clara disputa pela sua apropriação, uma vez que os recursos estão garantidos no orçamento do Estado. Este, por sua vez, transforma-se em uma arena, na qual diferentes setores do tecido social buscam defender seus interesses. ${ }^{26}$

No que se refere ao Brasil, Mendes ${ }^{27}$ destaca que o fundo público teve seus contornos de atuação limitados, quer seja na configuração do financiamento do Estado de modo geral, quer seja para a ampliação 
ou, até mesmo, da manutenção da viabilidade das políticas sociais. A análise do percurso da concentração de renda no País ao longo do século $X X$ demonstra que os processos de dominação, acumulação e distribuição da riqueza adquiriram características próprias, diferentes daquelas experimentadas nos países do capitalismo central.

Somente com o advento da Constituição Federal de 1988 ocorre uma mudança no modelo de financiamento com a criação do Orçamento da Seguridade Social, que se configurou com parte do fundo público existente na sociedade brasileira, especialmente importante para a viabilidade das políticas orientadas para a área social.

Diante disso, o fundo público no País se configura em um dos principais alvos de interesse. Sua lógica de atuação é forçar o aumento das despesas com juros da dívida pública no orçamento federal. Logo, apropria-se de parte do fundo público, graças à remuneração dos títulos públicos do governo, que são posteriormente negociados no lucrativo sistema financeiro. ${ }^{27,28}$

Essa forma de atuação do capital vem impondo prejuízos aos cofres públicos, a tal ponto de fragilizar a capacidade dos Estados em viabilizar suas políticas sociais, sobretudo aqueles que adotaram sistemas de proteção social universais, como é o caso do Brasil. Em se tratando particularmente da saúde, expressa como direito na constituição brasileira, viu-se ameaçada no que se refere a garantir o princípio da universalidade. Uma das formas mais claras desse movimento, no contexto brasileiro, deu-se com a criação da Desvinculação das Receitas da União (DRU), cuja renovação foi admitida pelo Congresso Nacional até 2023. Seu objetivo é promover a retirada de $20 \%$ dos recursos do Orçamento da Seguridade Social, a fim de manter o superávit primário, de modo a garantir o pagamento de juros da dívida pública. ${ }^{27}$

É nesse contexto, pautado na lógica do lucro a qualquer custo, com as redes de solidariedade social enfraquecidas, ditado pelos interesses do capitalismo, que as políticas sociais, a duras penas, estão inseridas.

Concordando com Marques, ${ }^{15}$ as políticas sociais passam a ocupar um "não lugar" no capitalismo contemporâneo, visto que se apresentam como entrave aos interesses do capital. Ao vislumbrar a reprodução do sistema sem a passagem pelo ciclo da produção, as políticas sociais deixam de ser interessantes para o funcionamento dessa estrutura. Logo, os sistemas públicos, entre eles o de saúde, passam a ser concebidos como "custos". Nesse cenário, sua privatização atenderia aos interesses do mercado e renderia vultosos lucros, proporcionando a manutenção do status quo, favorável às elites do país, detentoras dos meios de produção do capital.

\section{O papel dos organismos internacionais na construção das agendas dos países periféricos: o case do Banco Mundial na Saúde Brasileira}

As transformações ocorridas no mundo no pós-Segunda Guerra foram cruciais para o estabelecimento de uma nova ordem mundial. De forma peculiar, a estruturação do arcabouço jurídico e econômico dessa nova ordem contou com a atuação estratégica das grandes agências internacionais. Entre estas, cabe destacar aquelas ligadas ao mundo das finanças e do comércio, como o Banco Mundial, a Organização Internacional do Trabalho, o Programa das Nações Unidas para o Desenvolvimento e o Fundo Monetário Internacional. 
Em se tratando particularmente do Banco Mundial, esse organismo foi criado durante a conferência de Bretton Woods em 1944, com o propósito de servir como arcabouço institucional multilateral, cuja missão refere-se à garantia da estabilidade social, econômica e financeira, em um mundo que acabara de sair de uma guerra sem precedentes. Seu objetivo central era assegurar a possibilidade da atividade comercial internacional, onde não houvesse restrições, impedimentos ou fronteiras. ${ }^{29}$

Somente a partir dos anos 1980 o Banco Mundial dá início a um novo ciclo em sua história. Ao propagar as ideias que compunham a "reforma" do Estado, com vistas a contornar a crise vivida pelo sistema capitalista, assume uma agenda descolada da anterior, que se restringia à infraestrutura. Assim, propõe aos países devedores a oferta de empréstimos de ajuste estrutural, desde que estes se comprometessem a cumprir as exigências impostas pelo credor. ${ }^{30} \mathrm{O}$ intuito era possibilitar o equilíbrio da macroeconomia dos países que haviam contraído a dívida, de modo a reinseri-los na rota do mercado internacional.

No entanto, a subordinação dos Estados a tais medidas culminou em uma série de reformas no setor público, e uma nova dinâmica de aproximação com o mercado. Conforme destaca Vilas, ${ }^{31}$ as condições para obter os empréstimos de ajuste estrutural significaram uma transformação severa dos objetivos e das funções do setor público e da organização político-institucional do Estado. Sustentando essa transformação, emerge a ideia de que a crise - causada pela adaptação às novas condições da economia mundial - era determinada pelo excessivo intervencionismo estatal, do qual derivava uma destinação de recursos ineficiente. ${ }^{31}$

A política de financiamento do Banco Mundial passa, então, a mirar as políticas sociais, tendo como premissa a noção de que estas são necessárias ao "combate à pobreza". ${ }^{8,23}$ Nesse sentido, o Banco Mundial passa a lançar uma série de relatórios, sobretudo para os países em desenvolvimento, contendo recomendações para áreas importantes, como a educação e a saúde. Além de serem políticas estratégicas, do ponto de vista do alcance populacional, esses dois setores detêm uma parte significativa do orçamento dos Estados, sendo, portanto, alvo de disputas.

Especialmente no que tange ao setor saúde, vários pesquisadores ${ }^{8,32,33}$ têm empregado seus esforços na tentativa de compreender os efeitos da influência do Banco Mundial sobre as políticas de saúde no Brasil, desde o início dos anos 1990. Ainda hoje, configura-se em importante tema de debate na atualidade, uma vez que o ideário liberal não comporta o direito universal à saúde. ${ }^{34}$ Nessa linha de pensamento a saúde deve ser tratada como um bem de consumo, sendo o mercado o responsável pela oferta. ${ }^{34}$

Assim, ao Estado seria atribuído a função de regular a oferta e garantir "mínimos essenciais" pois, supostamente, o mercado seria quem melhor organizaria a produção, distribuição e o consumo do mesmo. ${ }^{34}$ Ainda caberia ao Estado a organização das ações tradicionais de saúde pública, com vistas a controlar epidemias e riscos que possam vir a desestruturar o mercado. ${ }^{34}$

Na concepção do Banco Mundial, um sistema de saúde para os países em desenvolvimento deveria abrir mão do tratamento clínico, dos avanços científicos e tecnológicos logrados na área. O pensamento dessa instituição interfere diretamente na APS ao sugerir a criação de serviços de saúde pública que se restrinjam à assistência básica, com utilização de procedimentos simples e de baixo custo, realizados por profissionais pouco qualificados, com o intuito de resolver questões mais gerais no âmbito da saúde, que abarcam um caráter mais familiar e comunitário. ${ }^{8}$ 
Entre outras medidas práticas, estabelece a flexibilização de procedimentos, a separação entre formulação e implementação e a introdução de elementos de mercado na administração pública. Propõe também novas formas de provisão dos serviços, baseadas na criação de entidades não estatais, na descentralização e na privatização de funções públicas, tendo como pré-requisito a redução do tamanho do Estado e dos gastos públicos. ${ }^{35}$

Tais medidas foram propagadas sob a égide de teorias administrativas que ficaram conhecidas como Nova Gestão Pública. Nesse contexto, as reformas da saúde procuraram promover, inicialmente, a descentralização, o fomento à criação de mercados privados de asseguramento, a introdução de copagamentos nas unidades públicas de saúde e a focalização do Estado nas populações ditas "pobres". ${ }^{36}$

Em trabalho recente, publicado por Rizzoto e Campos, ${ }^{34}$ os autores analisaram dois relatórios publicados pelo Banco Mundial neste início de século XXI. O primeiro, publicado em 2007, intitula-se "Governança no Sistema Único de Saúde (SUS) Brasileiro - fortalecendo a qualidade dos investimentos públicos e da gestão de recursos". Já o segundo, lançado em 2013, tem por título "20 anos de construção do sistema de saúde no Brasil: uma análise do Sistema Único de Saúde". Decorridos mais de duas décadas desde o último relatório endereçado ao SUS, datado no ano de 1991, os autores avaliam que os objetivos dos relatórios continuam os mesmos: seu foco permanece ancorado no financiamento, da relação com o mercado e da gestão do Estado. ${ }^{34}$

Diante do exposto, é fundamental destacar que esse processo se dá em um contexto internacional e nacional de maturidade do complexo médico-industrial-financeiro da saúde, o qual se encontra em franca expansão. Tal articulação está sob a égide de grandes empresas multinacionais dos países desenvolvidos, cujos padrões de atenção à saúde se disseminam em associação com grandes empresas nacionais de seguros e serviços de saúde. ${ }^{36}$

Logo, as propostas do Banco Mundial para o setor saúde dirigem-se ao Estado, no sentido de limitá-lo em suas funções. Dessa maneira, desvirtua a concepção de direito à saúde como conquista social, relegando-a a condição de mercadoria, ou seja, a saúde torna-se objeto no jogo espúrio do mercado, orientado pela lógica do custo/benefício.

\section{Quanto ao futuro do SUS e da APS: políticas residuais ou retorno ao ideário da Reforma Sanitária?}

Face aos interesses explicitados na atual fase do capitalismo, por intermédio da ação do capital portador de juros, em sua forma mais fetichizada, denominado capital fictício, a manutenção das políticas sociais, e em especial as políticas de saúde, tornou-se um grande desafio. Sua organização e seu financiamento, conforme o ideário presente à época do Welfare State, orientada para a universalização, são agora compreendidos como custos, seguindo na contramão da própria noção ampliada de proteção social. Dessa forma, a continuidade dessas políticas, hoje, depende urgentemente da organização de setores da sociedade civil que se articulem em prol da defesa dos direitos sociais conquistados. ${ }^{37}$

As diretrizes do pensamento neoliberal têm reduzido a questão social à pobreza, ${ }^{23}$ o que afeta as características da chamada nova geração de políticas sociais. ${ }^{38}$ Amplamente disseminadas em todo o mundo pelas agências internacionais, tais medidas vão na contramão das políticas do Estado de Bem-Estar 
Social. Privilegiam a adoção de políticas focalizadas, seletivas e assistencialistas. Assim, o "combate à pobreza" assumiu centralidade e relegou as demais políticas sociais a um plano secundário, ou seja, suas diretrizes seguiram a mesma lógica ou estão voltadas, de algum modo, para aquele objetivo.

Essa nova concepção de política social traz em seu bojo aquilo que Netto ${ }^{39}$ cunhou como predomínio do "minimalismo", ou seja, políticas assistenciais que não apresentam qualquer intenção de eliminar a pobreza. Sua direção aponta de modo singular aos mais pobres, na tentativa de se contrapor às mazelas da indigência.

Como destaca Mauriel, ${ }^{38}$ toda política social revela uma determinada concepção de sociedade. Logo, diante de um contexto socioeconômico marcado pela individualidade e pela força do capital especulativo, faz-se necessário o debate sobre a viabilidade até mesmo dessas políticas minimalistas. Tal reflexão deriva do entendimento de que a própria conformação dessas políticas já começa a ser contestada, uma vez que deixam de ser interessantes ao capital, em seu objetivo de alcançar lucros cada vez mais vultosos. Dessa forma, Leite ${ }^{37}$ indaga sobre a possibilidade de as sociedades capitalistas rumarem para a adoção de políticas residuais, ou seja, políticas sociais de caráter público, que servem de algum modo aos interesses do capital, de modo a se tornarem campo de sua ação.

Face ao exposto, a viabilidade de políticas sociais de caráter universal como o SUS torna-se um imenso desafio. Para além dos constrangimentos financeiros que acompanham o sistema desde a sua criação, o que está em jogo é a sua capacidade de manutenção do direito constitucional à saúde, conquistado com ampla articulação de diversos setores da sociedade. Desse modo, é preciso destacar que o SUS é resultado do projeto que deu origem à reforma sanitária brasileira. Está estruturada como política de saúde de natureza macrossocial, na qual se faz presente um leque de políticas específicas, como atenção básica, urgência e emergência, e promoção da saúde, articulando diversas práticas de saúde. ${ }^{39}$

Conforme salienta Paim, ${ }^{40}$ a Reforma Sanitária, do ponto de vista da reforma social, prezava pela defesa e democratização do Estado e da sociedade. Nessa perspectiva, compreendia a saúde como objeto de disputa política, arena na qual as forças sociais buscavam assegurar os seus interesses. Desse modo, apesar das contradições impostas ao sistema desde a sua criação, é inegável o êxito logrado pelo SUS.

Todavia, todo esse avanço está sob ameaça, com o avanço de políticas conservadoras, que enxergam a saúde como mercadoria. O maior sistema público e universal de saúde do mundo é alvo da especulação financeira, que drena os recursos destinados ao setor, impondo sérias restrições a sua permanência.

Assim, diante desse cenário adverso, a pergunta que se coloca diz respeito aos rumos do SUS: a população brasileira caminhará para um sistema residual, destinado exclusivamente aos miseráveis do país ou, em alguma medida, é possível rever a agenda da Reforma Sanitária, corrigindo seus erros, com vistas a materializar o SUS, tal qual se concebe na esfera constitucional?

Esse debate é particularmente relevante para a atenção primária. No período pós-Alma-Ata, modelagens distintas de APS foram postas em prática, ganhando destaque estratégias seletivas, centradas em grandes programas voltados a problemas relevantes em termos epidemiológicos, como o monitoramento do desenvolvimento infantil, amamentação, controle da reprodução feminina e atenção a doenças infecciosas 
prevalentes e de alta morbimortalidade. Tais modelos serviram de base para programas e estratégias de implantação de APS com escopo restrito de atenção à saúde dos mais vulneráveis. ${ }^{41}$

Contudo, a noção de APS seletiva entra em contradição com modelos mais robustos de atenção à saúde, que possuem enfoque em acesso oportuno a serviços de saúde abrangentes e resolutivos, e que prestam cuidados humanizados e integrais por longos períodos de tempo às pessoas tomadas em seu contexto comunitário, cultural e familiar. A construção qualificada de tais modelos requer investimentos significativos não apenas na estruturação de serviços, mas também na formação, valorização e fixação de profissionais de saúde de diversas categorias - medicina de família e comunidade, enfermagem de família e comunidade, psicologia, serviço social, entre outros. ${ }^{41}$

É neste sentido que o ideário neoliberal, cuja tradução na estruturação de políticas sociais de saúde discutimos nesse texto, pode representar um obstáculo à construção de uma APS robusta e qualificada que sirva de base e coordenação para sistemas de saúde equânimes e sustentáveis.

\section{Considerações finais}

As transformações oriundas do processo de acumulação capitalista têm ampliado seu escopo de atuação no tecido social, em uma velocidade jamais vista na história. Face ao exposto, ao deixar de serem interessantes ao capitalismo financeiro, as políticas sociais vêm sendo alvo de ataques, de modo a tornar um desafio a sua materialização. Nesse contexto de apropriação, a saúde configura-se em um espaço privilegiado para a obtenção de lucro, no qual se abre uma gama de possibilidades de investimentos, visto que o setor se caracteriza por sua complexidade e diversidade de componentes estruturantes.

Ao relegar a saúde sob o prisma do combate à pobreza, retira-se a perspectiva da universalidade, dirigindo a focalização das ações àquela parcela da população desprovida dos mínimos recursos financeiros. O direito à saúde, conquistado com ampla articulação de importantes segmentos da sociedade brasileira, é alvo de constrangimentos, em prol de um discurso que a compreende como custo, e não como garantia de cidadania.

Ao explicitar sua posição em defesa da centralidade do mercado, o Banco Mundial assume o papel de grande ordenador, articulador e propositor da agenda dos Estados. Ao lançar suas prerrogativas na agenda global, aponta para a necessidade de reformas políticas e econômicas, que vislumbrem estratégia de redução dos custos que são destinados às políticas sociais.

Desse modo, durante estas quase três décadas de existência, o SUS tem sido alvo de duros ataques. A lógica do pensamento liberal-privatista, defendida pelo Banco Mundial, está disseminada em meio à concepção de sociedade de grande parte da população brasileira. Contudo, embora apresente sérios problemas relativos à sua estrutura, gestão do sistema, financiamento, entre outros, ainda segue com reconhecimento internacional devido à grande dimensão de sua cobertura. Vários são os programas de referência para o mundo todo.

Logo, faz-se urgente a aglutinação de forças daqueles que estejam, de fato, comprometidos com a consolidação do SUS e o fortalecimento da APS. 


\section{Contribuição dos autores}

Concepção e/ou delineamento do estudo: WSL; Aquisição, análise ou interpretação dos dados: WSL e FS; Redação preliminar: WSL; Revisão crítica da versão preliminar: WSL e FS.

Todos os autores aprovaram a versão final e concordaram com prestar contas sobre todos os aspectos do trabalho.

\section{Conflito de interesses}

Declaram não haver.

\section{Referências}

1. Fleury S, Ouverney AM. Política de saúde: uma política social. In: Giovanella L, Escorel S, Lobato, LVC, Noronha JC, Carvalho AI, orgs. Políticas e sistema de saúde no Brasil. Rio de Janeiro: Fiocruz; 2012. 1100 p.

2. Alves VS. Um modelo de educação em saúde para o Programa Saúde da Família: pela integralidade da atenção e reorientação do modelo Assistencial. Interface (Botucatu). 2005;9(16):39-52. http://dx.doi.org/10.1590/S1414-32832005000100004

3. Bahia L. O SUS e os desafios da universalização do direito à saúde: tensões e padrões de convivência entre o público e o privado no sistema de saúde brasileiro. In: Lima NT, Gerschman S, Edler FC, Suárez JC, orgs. Saúde e Democracia: história e perspectivas do SUS. Rio de Janeiro: Fiocruz; 2005. p. 407-49.

4. Behring ER, Boschetti IC. Políticas Sociais: Fundamentos e História. São Paulo: Cortez; 2008.

5. Barreto MI. As organizações sociais na reforma do Estado brasileiro. In: Bresser-Pereira L. O público não-estatal na reforma do Estado. Rio de Janeiro: Fundação Getúlio Vargas; 1999. p. 60-7.

6. Bresser-Pereira LC. A reforma gerencial do Estado de 1995. Rev Adm Pública. 2000;34(4):57-72.

7. Di Pietro MSZ. Parcerias na administração pública: concessão, permissão, franquia, terceirização, parceria público-privado e outras formas. 5ª ed. São Paulo: Atlas; 2005.

8. Rizzoto MLF. O Banco mundial e as políticas de saúde nos anos 90: um projeto de desmonte do SUS [Tese de doutorado]. Campinas: Faculdade de Ciências Médicas da Universidade Estadual de Campinas; 2000. 226 p.

9. Mandel E. O capitalismo tardio. São Paulo: Abril Cultural; 1982.

10. Pires MRGM, Demo P. Políticas de saúde e crise do Estado de Bem-Estar: repercussões e possibilidades para o Sistema Único de Saúde. Saúde Soc. 2006;15(2):56-71.

11. Arretche MTS. Emergência e Desenvolvimento do Welfare State: teorias explicativas. Rev Bras Inf Bibliogr Ciênc. 1995:39(1):3-40.

12. Netto JP. Economia Política: uma introdução crítica. 3ª ed. São Paulo: Cortez; 2007.

13. Harvey D. Condição pós-moderna. 21aㅡ ed. São Paulo: Loyola; 2011.

14. Marques RM, Nakatani P. O que é capital fictício e sua crise. São Paulo: Ed. Brasiliense; 2009.

15. Marques RM. O lugar das políticas sociais no capitalismo contemporâneo. Argumentum (Vitória ES). 2015;7(2):7-21. http://dx.doi. org/10.18315/argumentum.v7i2.10517

16. Behring ER. Política social no capitalismo tardio. $2^{\text {a }}$ ed. São Paulo: Cortez; 2002.

17. Klagsbrunn VH. Uma leitura crítica dos conceitos de mundialização do capital e de regime de acumulação com predominância financeira. Crit Marxista. 2008;27:27-46.

18. Chesnais F. A mundialização financeira: gênese, custos e riscos. São Paulo: Xamã; 1998.

19. Guttmann R. A transformação do capital financeiro. Econ Soc. 1996;7:51-83.

20. Granemann S. Fundos de pensão e a metamorfose do "salário em capital". In: Salvador E, Behring E, Boschetti I, Granemann S, orgs. Financeirização, fundo público e política social. São Paulo: Cortez; 2012. 
21. Pereira PA. Pluralismo de bem-estar ou configuração plural da política social sob o neoliberalismo. In: Boschetti I, org. Política Social: alternativas ao neoliberalismo. Brasília: Universidade de Brasília; 2004. p. 135-59.

22. Sen A. A perspectiva da liberdade. In: Sen A, ed. Desenvolvimento como liberdade. São Paulo: Companhia das Letras; 2000.

23. Ugá VD. A questão social como "pobreza": crítica à conceituação neoliberal [Tese de doutorado]. Rio de Janeiro: Instituto Universitário de Pesquisas do Rio de Janeiro; 2008.

24. Duménil G, Lévy D. O neoliberalismo sob a hegemonia norte-americana. In: Chesnais F Organizador, org. A finança mundializada. São Paulo: Boitempo; 2005.

25. Draibe SM. As políticas sociais e o neoliberalismo - Reflexões suscitadas pelas experiências latino-americanas. Rev USP. 1993;17:86101. http://dx.doi.org/10.11606/issn.2316-9036.v0i17p86-101

26. Salvador E. Fundo público e políticas sociais na crise do capitalismo. Serv Soc Soc. 2010;104:605-31. http://dx.doi.org/10.1590/S010166282010000400002

27. Mendes A. O fundo público e os impasses do financiamento da saúde universal brasileira. Saúde Soc. 2014;23(4):1183-97.

28. Behring ER. Crise do Capital, fundo público e valor. In: Boschetti I, Behring EA, Santos SMM, Mioto RCT, orgs. Capitalismo em crise, política social e direitos. São Paulo: Cortez; 2010.

29. Lichtenszteyn S. Bae M. Fundo Monetário Internacional e Banco Mundial: Estratégias e Políticas do Poder Financeiro. São Paulo: Brasiliense; 1987.

30. Almeida CO. Banco mundial e as reformas contemporâneas do setor saúde. In: Pereira JMM, Pronko M, orgs. A Demolição de direitos: um exame das políticas do Banco Mundial para a educação e a saúde: 1980-2013. Rio de Janeiro: Escola Politécnica de Saúde Joaquim Venâncio; 2014.

31. Vilas CM. O Banco Mundial e a reforma do Estado na América Latina: fundamentos teóricos e prescrições políticas. In: Pereira JMM, Pronko M, orgs. A demolição de direitos: um exame das políticas do Banco Mundial para a educação e a saúde: 1980- 2013. Rio de Janeiro: Escola Politécnica de Saúde Joaquim Venâncio; 2014.

32. Mattos RA. As agências internacionais e as políticas de saúde nos anos 90: um panorama geral da oferta de idéias. Ciênc Saúde Coletiva. 2001;6(2):377-89. http://dx.doi.org/10.1590/S1413-81232001000200008

33. Pereira JMM, Pronko M. A demolição de direitos: um exame das políticas do Banco Mundial para a educação e a saúde: $1980-2013$. Rio de Janeiro: Escola Politécnica de Saúde Joaquim Venâncio; 2014.

34. Rizzoto MLF, Campos GWS. O Banco Mundial e o Sistema Único de Saúde brasileiro no início do século XXI.Saúde Soc.2016;25(2):26376.

35. Rizzoto MLF. O Banco Mundial e o sistema nacional de saúde no Brasil. In: Pereira JM M, Pronko M, orgs. A demolição de direitos: um exame das políticas do Banco Mundial para a educação e a saúde: 1980- 2013. Rio de Janeiro: Escola Politécnica de Saúde Joaquim Venâncio; 2014.

36. Andreazzi MFS, Bravo MIS. Privatização da gestão e organizações sociais na atenção à saúde. Trab Educ Saúde. 2014;12(3):499-518. http://dx.doi.org/10.1590/1981-7746-sip00019

37. Leite IC. Rumo a políticas sociais residuais? Argumentum (Vitória ES). 2015;7(2):24-31.

38. Mauriel APO. Fundamentos do combate à pobreza na contemporaneidade: Amartya Sen e a perspectiva do desenvolvimento humano. In: Seraine ABMS, Santos Junior RB, Miyamoto S, orgs. Estado, desenvolvimento e políticas públicas. Ijuí: Unijuí; Teresina: Universitária da UFP; 2008. p. 87-128.

39. Netto JP. Crise do capital e consequências societárias. Serv Soc Soc. 2012;111:413-49. http://dx.doi.org/10.1590/S010166282012000300002

40. Paim JS. Uma análise sobre o processo da Reforma Sanitária Brasileira. Saúde Debate. 2009;33(81):27-37.

41. Starfield B. Atenção primária: equilíbrio entre necessidade de saúde, serviços e tecnologia. Brasília: UNESCO, Ministério da Saúde; 2004. 